\title{
Electron Microscopic Alterations in Pediculus humanus capitis Exposed to Some Pediculicidal Plant Extracts
}

\author{
Dina M. H. El Akkad*, Naglaa Saad M. El-Gebaly, Hebat-Allah Salah A. Yousof, Mousa A. M. Ismail \\ Department of Parasitology, Faculty of Medicine, Cairo University, Cairo, Egypt
}

\begin{abstract}
Head lice, Pediculus humanus capitis, infestation is an important public health problem in Egypt. Inadequate application of topical pediculicides and the increasing resistance to the commonly used pediculicides made the urgent need for the development of new agents able to induce irreversible changes in the exposed lice leading to their mortality. The aim of the present work is to evaluate pediculicidal efficacy of some natural products such as olive oil, tea tree oil, lemon juice, and ivermectin separately in comparison with tetramethrin-piperonyl butoxide (licid), as a standard pediculicide commonly used in Egypt. The effects of these products were evaluated by direct observation using dissecting and scanning electron microscopes (SEM). Results showed that after $1 \mathrm{hr}$ exposure time in vitro, absolute (100\%) mortalities were recorded after exposure to $1 \%$ ivermectin and fresh concentrate lemon juice. The mortalities were decreased to $96.7 \%$ after exposure to tea tree oil. Very low percentage of mortality (23.3\%) was recorded after $1 \mathrm{hr}$ of exposure to extra virgin olive oil. On the other hand, the reference pediculicide (licid) revealed only mortality rate of $93.3 \%$. On the contrary, no mortalities were recorded in the control group exposed to distilled water. By SEM examination, control lice preserved outer smooth architecture, eyes, antenna, respiratory spiracles, sensory hairs, and legs with hook-like claws. In contrast, dead lice which had been exposed to pediculicidal products showed damage of outer smooth architecture, sensory hairs, respiratory spiracles and/or clinching claws according to pediculicidal products used.
\end{abstract}

Key words: Pediculus humanus capitis, pediculicide, plant extract, in vitro, scanning electron microscope

\section{INTRODUCTION}

Head lice, Pediculus humanus capitis, infestation affect millions of schoolchildren worldwide [1]. In Egypt, head lice infestation is an important public health problem and about $22 \%$ of school students in a study carried out in Cairo was lice-infested [2]. The global control of pediculosis has been hampered as a result of incorrect use of topical insecticides, and the increasing resistance to the commonly used pediculicides, including lindane, malathion, and permethrin [3]. Therefore, there is an urgent need for the development of new effective pediculicidal products for the market.

Trials against lice were done by previous workers. Shrivastava et al. [4] tried undiluted lemon which caused complete cessation of movements of lice adults after $25 \mathrm{~min}$. Lee and his colleagues [5] tested olive oil in 2004. Tea Tree Gel appeared

\footnotetext{
- Received 2 January 2016, revised 8 May 2016, accepted 9 May 2016.

*Corresponding author (elakkaddina@yahoo.com)

(C) 2016, Korean Society for Parasitology and Tropical Medicine

This is an Open Access article distributed under the terms of the Creative Commons Attribution Non-Commercial License (http://creativecommons.org/licenses/by-nc/4.0) which permits unrestricted non-commercial use, distribution, and reproduction in any medium, provided the original work is properly cited.
}

to have been quite effective in a study done by Heukelbach et al. [6]. Permethrin $1 \%$ was tested in the same work. Also, in a previous work [7], no lice survived over $5 \mathrm{~min}$ at $50 \mathrm{ng} / \mathrm{ml}$ of ivermectin. However, almost none of the previous workers had studied the ultrastructural changes produced by these drugs and made beneficial comparisons except for ivermectin.

The aim of the present work was to evaluate pediculicidal efficacy of some natural products, including olive oil, tea tree oil, and lemon juice as well as ivermectin, each was tried separately, in comparison with tetramethrin-piperonyl butoxide (licid), as a standard pediculicide commonly used in Egypt against Pediculus humanus capitis in vitro. Adverse effects of these products on the exposed dead lice were evaluated by direct observation using dissecting and scanning electron microscopes (SEM) for better understanding of their mechanisms of action. In this study, we focused on electron microscopic changes detected in adult lice after exposure to the lethal doses of these previously used agents by the mentioned workers.

\section{MATERIALS AND METHODS}

This study was assessed and approved by Ethics Committee 
of Faculty of Medicine, Cairo University, Egypt after taking consents from local health authorities and all participants.

\section{Collected samples}

Lice were collected from schoolchildren as well as lice-infested patients attending skin outpatient clinic at Kasr Al Ainy hospital. Samples were brought by combing through their hair using clean combs. Head lice were carefully gathered in a glass container with silk cloth cover to allow for proper ventilation. All the volunteered patients had not been treated with any anti-lice products for the preceding 3 months.

\section{Tested products}

Fresh fruits of lemon (Citrus lemon) were purchased from a local market of Cairo. Lemon fruits were peeled and squeezed by hand machine under standard pressure. The juice was allowed to settle for $10 \mathrm{~min}$ at room temperature $\left(22-25^{\circ} \mathrm{C}\right)$. Raw undiluted lemon juice was obtained after filtering through metal thieves ( 25 pores/inch).

Olive oil as a traditional home remedy for eradication of lice was brought as extra virgin olive oil provided by Wadi Company for food industries. Tea Tree Head Lice Gel kit, containing Melaleuca (tea tree) oil 5\% and ethanol 20\%, was provided from Thursday Plantation Laboratories (Ballina, New South Wales, Australia). Ivermectin lotion 1\% (each $100 \mathrm{ml}$ contains $1 \mathrm{~g}$ ivermectin) as effective anti-lice anti-scabitic was provided by Unipharma (Athens, Greece). Licid lotion (each $100 \mathrm{~g}$ contains tetramethrin $0.6 \mathrm{~g}$, piperonyl butoxide $2.4 \mathrm{~g}$ ) as effective pediculicide was obtained from Misr Company (Cairo, Egypt) for pharmaceuticals (used as the reference drug).

\section{Inclusion criteria}

The collected lice were transferred onto filter paper discs (Whatman No. 1) fitting in 5-cm Petri dishes at $27^{\circ} \mathrm{C}$ and $50 \%$ relative humidity. They were examined for the activity and morphological criteria under a dissecting microscope. They were identified according to Burkart et al. [8]. Only actively motile and intact adult lice were selected for the test irrespective of sex.

\section{In vitro pediculicidal activity}

According to Shrivastava et al. [4], the collected fresh, sound and intact lice were divided into 6 experimental groups, each of 10 lice. Three replicates were done and the average was estimated. The previous products were tested in vitro against lice in comparison with the reference drug (licid) and the negative control in distilled water. The exposure was done according to the method of Shrivastava et al. [4] with little modification. In each replicate, $0.5 \mathrm{ml}$ of each test solution was spread over the lice and the filter paper in each of the 6 experimental groups [9]. For the negative control group, $0.5 \mathrm{ml}$ of distilled water was spread in the same way to prevent lice from desiccation.

Lice were exposed to the tested products simultaneously for $1 \mathrm{hr}$. At the end of the exposure time, lice were washed in tap water 3 times and placed into a new Petri dish over a new filter paper [6]. Lice were left for another $1 \mathrm{hr}$, then re-examined under a dissecting microscope where the number of dead and alive individuals was counted.

\section{Criteria of mortality}

According to Shrivastava et al. [4], lice on the filter paper were examined under a dissecting microscope. Death of lice was defined as those showing complete cessation of all vital signs and movement of antennae or legs, with or without stimulation using a forceps, heat or light exposure.

\section{Electron microscopic study}

It was done in Drinking Water for Greater Cairo Company, the central laboratory, Fustat, microbiology laboratory. In order to investigate the adverse effects of the tested drugs on exposed lice, samples were examined under an electron microscope and compared with the negative control lice. Adults were observed under low-vacuum SEM. The samples were washed in distilled water and dried at room temperature. Specimens were mounted on stubs with double side carbon tape [10]. Then, the samples were inspected on JEOL JSM6390LA analytical SEM.

\section{RESULTS}

The results displayed in Table 1 demonstrated the percent-

Table 1. Rate of mortality in 30 exposed lice to different tested products in comparison with the control

\begin{tabular}{|c|c|c|}
\hline \multirow{2}{*}{ Tested product } & \multicolumn{2}{|c|}{ Mortality in exposed lice $($ no. $=30$ ) } \\
\hline & No. of dead lice & Mortality (\%) \\
\hline Lemon juice & 30 & 100.0 \\
\hline Ivermectin & 30 & 100.0 \\
\hline Tea tree oil & 29 & 96.7 \\
\hline Olive oil & 7 & 23.3 \\
\hline Licid & 28 & 93.3 \\
\hline Control & 0 & 0 \\
\hline
\end{tabular}



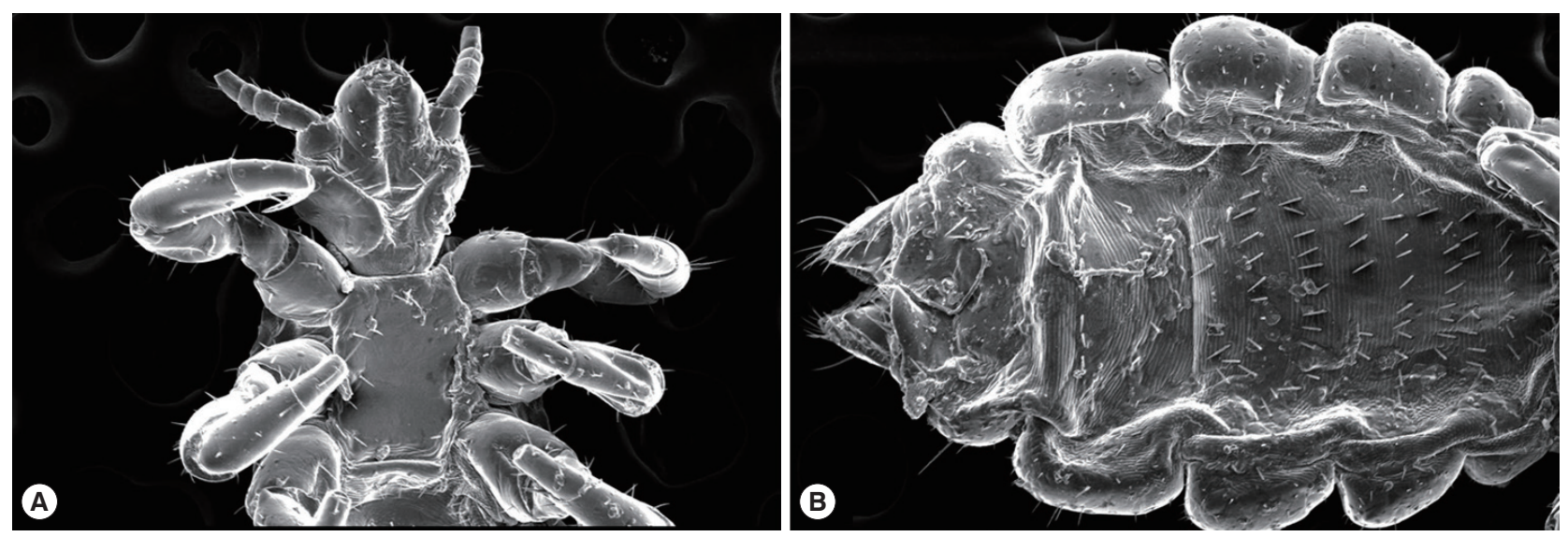

Fig. 1. SEM of a negative control louse (Pediculus humanus capitis, female) with preserved smooth outer contour with a conical head, ventral constriction, and blunt abdomen. (A) Antennae and eyes are intact with preserved 3 pairs of hairs at the end of the head anteriorly. The thorax is preserving pro-, meso-, and metathorax, and 3 pairs of legs terminated with hook-like claws. Sensory hairs could be identified on the legs. Setae are well preserved. (B) Abdominal respiratory spiracles could be detected and joint spaces demonstrate the contrast between the hard body chitin and the highly flexible soft chitin. The ventral aspect of the abdomen shows preserved gonopods.

age of mortalities in 30 exposed lice for different chemicals and control after $1 \mathrm{hr}$ of exposure (in vitro) using a dissecting microscope. The data revealed that $1 \%$ ivermectin and fresh concentrate lemon juice appeared to be potent pediculicides as they caused death of all the exposed lice (100\% efficacy). In the second rank after both products, tea tree oil showed the mortality rate of $96.7 \%$ as 1 of 30 lice exposed was still alive. Moreover, very low percentage of mortality (23.3\%) was recorded with extra virgin olive oil after the same period of exposure. On the other hand, 2 lice from the exposed 30 were still alive after exposure to the reference pediculicide (licid) reaching a mortality rate of $93.3 \%$. At the same time, no mortalities were recorded in the control group exposed to distilled water as the lice were still active preserving righting reflex.

The adverse effects of these products were evaluated by direct observation using scanning electron microscopes and the ultrastructural changes produced were recorded. SEM of negative control specimens showed smooth outer contour of adult lice and a conical head with a ventral constriction. Antennae and eyes were intact with preserved 3 pairs of hairs at the end of the head anteriorly. The thorax was intact with preserved pro-, meso-, and metathorax. Three pairs of legs were terminated with hook-like claws. Sensory hairs could be identified on the legs acting as chemoreceptors and mechanoreceptors. Setae were also preserved. Abdominal respiratory spiracles could be detected. The ventral aspect of the abdomen showed preserved gonopods (female Pediculus) (Fig. 1).

Ivermectin-treated specimens showed disfigured adult lice with apparently flaccid legs. There was damage of the chitinous covering of the head, its front, the last pair of legs, and basal apodeme. Loss of hook-like claws as well as tibial spurs was detected. There was loss of some of sensory hairs on legs. Less setae were observed as compared with the negative control. SEM micrographs illustrated destruction in the last abdominal segments as well as the edeagus and endotheca (Fig. 2A, B).

Citrus lemon juice-treated specimens illustrated shriveled, disfigured, and distorted adult Pediculus with loss of the outer smooth architecture as well as loss of clinching claws (Fig. 2C). Tea tree oil 5\%-treated Pediculus showed damage in clypeus and front of the head. Moreover, there was bulging of respiratory spiracles with intact antenna. Outer contour and hooklike claws were preserved. Abdomen maintained pseudopenis, edeagus, and subgenital plate (male Pediculus) (Fig. 2D). Extra virgin olive oil-treated lice showed that olive oil seemed to fill the respiratory system represented by the 2 hollow tubes on both sides and the abdomen together with their lateral extensions connected to the respiratory spiracles (Fig. 2E). There were no major ultrastructural changes in positive control specimens (tetramethrin-piperonyl butoxide-treated lice) except from some loss of sensory hairs and setae on the adult lice with some damage of the smooth outer architecture (Fig. 2F) as compared with the negative control.

\section{DISCUSSION}

The use of natural products of plant origin is the focus of at- 

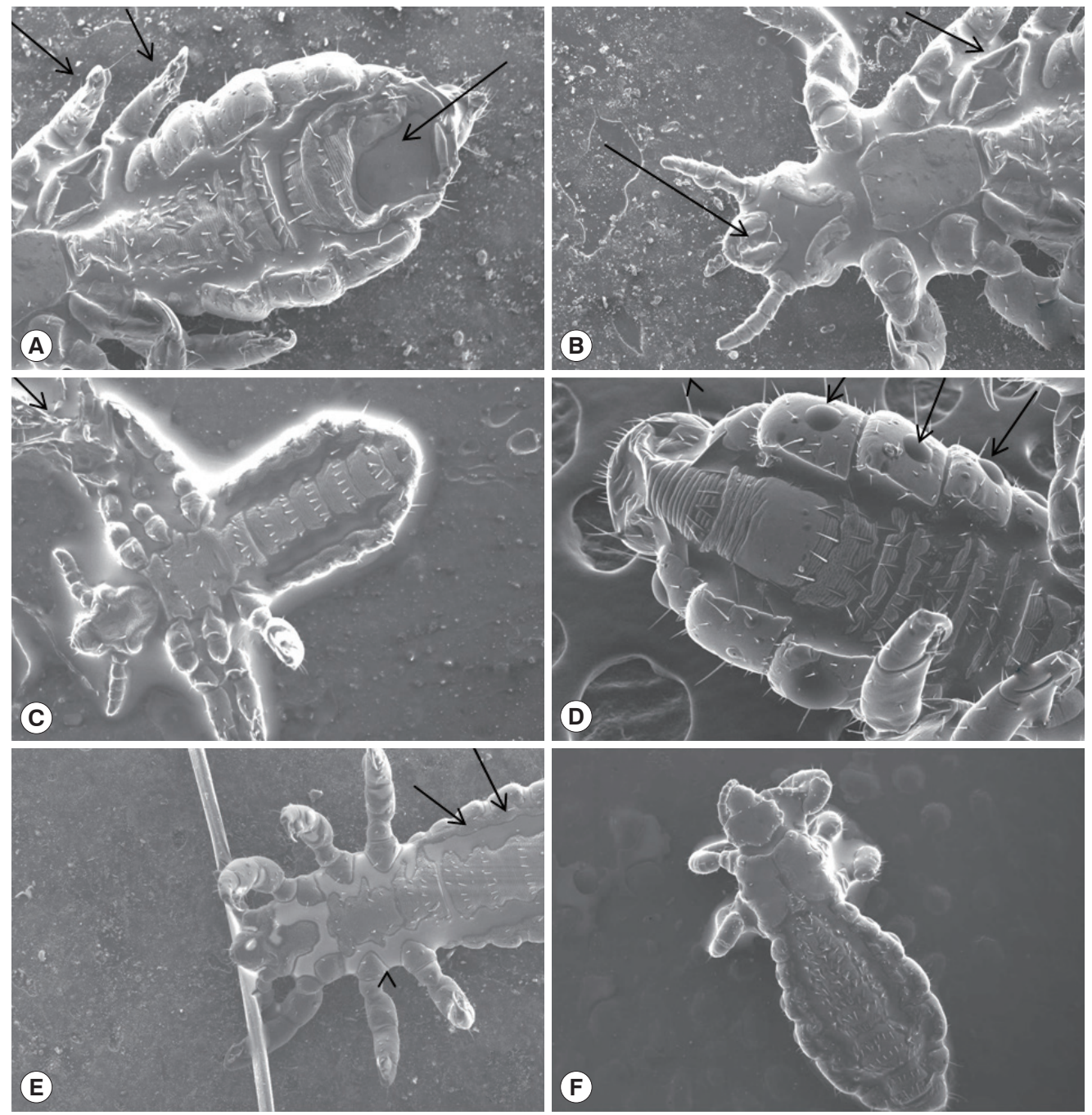

Fig. 2. SEM of drug-treated lice showing disfigured and damaged bodies. (A, B) An adult louse treated with ivermectin which shows apparently flaccid legs (short arrows), damage of the chitinous covering of the head, its front, the last pair of legs, and basal apodeme, and loss of hook-like claws as well as tibial spurs. Loss of some sensory hairs on legs, less setae as compared with the negative control, and destruction in the last abdominal segments (long arrow) as well as the edeagus and endotheca are seen. (C) Citrus lemon juice-treated lice illustrating shriveled, disfigured, and distorted adult Pediculus with loss of the outer smooth architecture as well as loss of clinching claws. (D) Tea trea oil 5\%-treated lice showed bulging of respiratory spiracles (arrows) with preserved outer contour and presence of hook-like claws. Abdomen maintained pseudopenis, edeagus, and subgenital plate. (E) Extra virgin olive oil-treated lice which show the respiratory system filled with olive oil along the 2 hollow tubes on both sides together with their lateral extensions connected to the respiratory spiracles (arrows). (F) Positive control specimens (licid-treated lice) illustrating some loss of sensory hairs and setae with some damage of the smooth outer architecture.

tention. They are suitable alternative to synthetic chemicals as they are readily biodegradable, of low cost, easily available and usually lacking toxicity to higher animals which means that they are eco-friendly [11]. In the current study, ivermectin showed marvelous pediculicidal effects. The injurious effect of ivermectin has been detected by Allam and his colleagues [7] who have noticed that no lice survived over $5 \mathrm{~min}$. This was probably due to different drug concentration used. The mech- anism of action of ivermectin might be due to possible muscle paralysis. Pariser et al. [14] have claimed to topical ivermectin $0.5 \%$ lotion killed head lice by increasing chloride in muscle cells, causing hyperpolarization and paralysis. They have stated that, when the treated eggs hatched, the lice were not viable because they could not feed as a result of pharyngeal muscle paralysis. Ivermectin-treated lice have shown loss of setae and some of sensory hairs on legs which might act as mechanore- 
ceptors as concluded by Burkhart et al. [8]. They also declared that sensory hairs, conical pegs, and campiniform organs identified on legs appeared to act as chemoreceptors, proprio receptors, and mechanoreceptors allowing lice to detect hazards such as chemical signals, wind, and combing through hair [8].

Moreover, this study pointed out the absolute efficacy of fresh lemon juice which coincided with the report of Shrivastava et al. [4] who confirmed that raw Citrus limon juice and $1 / 2$ diluted juice showed pediculicidal efficacies of $95 \pm 5 \%$ and $90 \pm 10 \%$, respectively. Tea tree oil has provoked high efficacy and bulging of respiratory spiracles which might lead to suffocation of lice in agreement with Heukelbach et al. [6] who emphasized the effectiveness of tea tree oil [6].

Extra virgin olive oil appeared to be the least effective. The same was reported by Lee et al. [5] who declared that no home remedy killed 100\% of lice or eggs after $24 \mathrm{hr}$. They also pointed out that olive oil might reduce egg hatchability. This was probably due to sealing of eggshell opening causing oxygen deprivation. Licid has illustrated low efficacy which may indicate the possible resistance to the compound. Hunter and Baker [12] found a high degree of resistance to permethrin in head louse in a Townsville school. Also, Heukelbach et al. [6] observed that $18 \%$ of lice were not dead at $3 \mathrm{hr}$ indicating some resistance to permethrin $1 \%$. The difference between percentage of mortality in the present study and that done by Heukelbach et al. [6] may be due to different ways in the application methodology. Furthermore, we used tetramethrin-piperonyl butoxide instead of permethrin $1 \%$. Tetramethrin is known to be one of the 1st generation pyrethroids which were known to act by prevention of closure of the voltage-gated sodium channels in the axonal membranes causing permanent depolarization thus paralyzing lice. Tetramethrin activity was also enhanced by addition of the synergist piperonyl butoxide as it was thought to inhibit microsomal cytochrome P450 enzymes responsible for metabolizing pyrethroids [13].

Negative control adults have remained alive throughout the whole exposure in agreement with other workers [4-6]. SEM of negative control has demarcated preserved outer smooth architecture which resembled the findings illustrated by Dutra et al. [10] who studied mummified adult lice. In that study, authors declared that adult lice showed a very well preserved state maintaining apparent lateral spiracles, eyes, and genital aperture in females.

In conclusion, ivermectin and fresh Citrus lemon juice have proved high pediculicidal efficacy followed by tea tree oil. Ex- tra virgin olive oil seemed to show least efficacy as compared with the positive and negative control lice. SEM studies showed variable ultrastructural changes which may highlight the mechanism of action of these agents against lice. The authors recommended further studies on the same materials after preparing them in more purified form. This may facilitate using them in more economic concentration to create new effective agents without drug resistance.

\section{ACKNOWLEDGMENTS}

All authors contributed to the idea of this paper, study design, collection of materials, methodology, and writing of the paper and revising it. We would like to thank Professor Dr. Mohamed El Bahy, Head of Parasitology Department, Faculty of Veterinary Medicine, Cairo University for his continuous help, support, and special guidance.

\section{CONFLICT OF INTEREST}

The authors declare that they have no competing interests.

\section{REFERENCES}

1. Magalhães P, Figueiredo EV, Daniel P, Capingana DP. Head lice among primary school children in Viana, Angola: prevalence and relevant teachers' knowledge. Libertas Academica. Human Parasit Dis 2011; 3: 11-18.

2. Morsy T, El-Ela RG, Mawla MY, Khalaf SA. The prevalence of lice infesting students of primary, preparatory and secondary schools in Cairo, Egypt. J Egypt Soc Parasitol 2001; 31: 43-50.

3. Greive KA, Barnes TM. In vitro comparison of four treatments which discourage infestation by head lice. Parasitol Res 2012; 110: 1695-1699.

4. Shrivastava V, Purwal L, Jain UK. In vitro pediculicidal activity of juice of Citrus limon. Int J Pharm Tech Res 2010; 2: 1792-1795.

5. Lee MT, Edman JD, Mullens BA, John M, Clark JM. Home remedies to control head lice: assessment of home remedies to control the human head louse, Pediculus humanus capitis (Anoplura: Pediculidae). J Pediatr Nurs 2004; 19: 393-398.

6. Heukelbach J, Canyon DV, Oliveira FA, Muller R, Speare R. In vitro efficacy of over-the-counter botanical pediculicides against the head louse Pediculus humanus var. capitis based on a stringent standard for mortality assessment. Med Vet Entomol 2008; 22: 264-272.

7. Allam SR, Sadaka HAH, Eissa MM, Rezk HA. In vitro effects of ivermectin on adult and developmental stages of two species of blood feeding arthropods. Acarid Phylogeny and Evolution. Adaptation in Mites and Ticks. 2002, pp 441-447. 
8. Burkhart CN, Burkhart CG, Gunning WT. Scanning electron microscopy of adult head lice (Pediculus humanus capitis) with focus on clinical implications. J Cutan Med Surg 2000; 4: 181-185.

9. Samuel AJSJ, Radhamani S, Gopinath R, Kalusalingam A, Vimala AGKA, Husain H. In vitro screening of anti-lice activity of Pongamia pinnata leaves. Korean J Parasitol 2009; 47; 4: 377-380.

10. Dutra JMF, Alves AD, Pessanha T, Rachid R, Souza WD, Linardi PM, Ferreira LF, Souza SMD, Araujo A. Prehistorical Pediculus humanus capitis infestation: quantitative data and low vacuum scanning microscopy. Rev Inst Med Trop Sao Paulo 2014; 56 : 115-119.

11. Yadav RP, Singh A. Efficacy of Euphorbia hirta latex as plant de- rived molluscicides against fresh water snails. Rev Inst Med Trop Sao Paulo 2011; 53: 101-106.

12. Hunter JA, Baker SC. Susceptibility of head lice (Pediculus humanus capitis) to pediculicides in Australia. Parasitol Res 2003; 90: 476-478.

13. Soderlund DM, Clark JM, Sheets LP, Mullin LS, Piccirillo VJ, Sargent D, James T, Stevens JT, Weiner ML. Mechanisms of pyrethroid neurotoxicity: implications for cumulative risk assessment. Toxicology 2002; 171: 3-59.

14. Pariser DM, Meinking TL, Bell M, Ryan WG. Topical 0.5\% ivermectin lotion for treatment of head lice. Engl J Med 2012; 367: 1687-1693. 